Mr. A. R. Gurd (personal communication) has shown that the insertion of cemented or non-cemented prostheses, or Kuntchner nails, all produce similar and marked increases in the levels of fat in blood from the femoral vein. It is not surprising that fat is frequently found in the pulmonary vessels of these patients postoperatively. Not much significance can be attached to this finding unless it is combined with an assessment of cardiopulmonary function. Dr. Gresham and colleagues do not comment on fat in the systemic circulation of the patients who died following Thompson prostheses.

Patients undergoing femoral head replacement with Thompson prostheses are generally old, with pre-existing cardiopulmonary disorders. They are subjected to a second severe episode of stress at operation within a variable interval of the original trauma. A higher mortality rate in these patients compared to those undergoing total hip replacement may be related to the unsatisfactory general condition of the former and to the fact that they are suffering a second episode of stress.-We are, etc.,

M. L. JAMES R. S. M. LING Princess Elizabeth Orthopaedic Hospital, Erincess

${ }_{*}^{*}$ Dr. James and Mr. Ling are correct. The authors inform us that in the typescript of their paper the words "acetabular" and "femoral" were inadvertently transposed and thus lines 7 and 8 in the first paragraph on p. 619 read incorrectly.-ED., B.M.F.

\section{High Altitude and House-dust Mites}

SIR,-We were very interested to read the article ( 9 January, p. 82) on the relationship of house-dust mite populations and altitude. Nairobi has a major asthma problem, but is at an altitude of $5,500 \mathrm{ft}(1,650 \mathrm{~m})$. Protozal and helminthic infections do not appear to be important precipitating causes, but many patients give a history that suggests that house-dust mites may be precipitating factors. ${ }^{1}$ We therefore have made a search for house-dust mites. Mites have been readily found in dust collected from mattresses (100 live mites per $5 \mathrm{~g}$ of dust being an average yield), using the simplest methods only-direct examination of dust with a dissecting microscope. The mites were predominantly Dermatophagoides pteronyssinus, and this has been confirmed by A. $M$. Cunnington of the Agricultural Research Council Pest Infestation Laboratory, Slough, Bucks.

This preliminary finding supports the view put forward in the article that it is not so much the altitude as the climate that determines mite populations, and that in high altitude areas in the tropics where much of the year is warm and humid, the house-dust mite may be an important precipitating factor in asthma.-We are, etc.,

FloRENCE GitoHo Philip ReEs

\footnotetext{
Department of Medicine

University of Nairobi.

Kenya

Rees, M. C.. Rees, P. H., and Woodhead, B. in preparation.
}

\section{Human Prolactin}

SIR,-Your leading article (24 July p. 201) was an interesting review of the present situation. You touched only briefly upon clinical example which illustrates the action of prolactin-release-inhibiting hormone and hence supports the existence of prolactin. Namely, when patients with deficient pituitary function are stimulated with fertility drugs, such as clomiphene, and pregnancy ensues, more than adequate lactation occurs, and also these patients may show secondary amenorrhoea and galactorrhoea once delivered, owing to continued inhibition of prolactin release. The following case history illustrates this

The patient, a housewife now 36, had had no previous illnesses or operations. The menarche occurred at the age of 13, and menstruation continued normally for one year. The next year her periods were very slight and from the age of 15 she had no menstrual period unless it was artificially induced.

The patient had married at 28 years of age and was investigated four years later because of the secondary amenorrhoea. Thyroid function tests were normal and a metopirone test showed a normal adrenocorticotrophic response. Gonadotrophin levels were found to be low when assayed; no endometrium was obtained at curettage. A diagnosis of deficient pituitary function was made. The patient was treated with human menopausal gonadotrophin, and became pregnant after the second course. The pregnancy progressed satisfactorily though placental function tests began to fall near term.

A healthy male infant weighing 3,240 g was delivered by lower segment caesarean section at 38 weeks amenorrhoea. The baby was breast fed for five months though the patient continued to lactate once this was stopped. After the delivery the patient again failed to menstruate.

Now over one year after delivery the patient continues with secondary amenorrhoea and galactorrhoea.-I am, etc.,

Department of Obstetrics,

E. DAw

University of Dundee

\section{Hypoglycaemia in Infancy and Childhood}

SIR,-In your otherwise excellent leading article on "Hypoglycaemia in Infancy and Childhood" (17 July, p. 130) you use the word "insulinoma." This means a tumour derived from or composed of insulin, which is clearly absurd. What is wrong with "islet cell tumour"? If the suffix "oma" is considered essential then "residiocytoma" may be used.-I am, etc.,

JOHN M. ROBERTSON

Department of Pathology Bishop Auckland General Hospital,

SIR,- In the leading article "Hypoglycaemia in Infancy and Childhood" (17 July, p. 130) trearment with intravenous glucose was recommended for infants with asymptomatic neonatal hypoglycaemia. This course of action would be justified if treatment itself were free from risk and there were reasonable grounds to suspect that asymptomatic hypoglycaemia resulted in neurological damage. The evidence available fails to support either assumption.

Treatment with intravenous glucose carries with it the risk of osmolar disturbances, and when the umbilical route is chosen, as it frequently is for technical reasons, additional hazards are incurred. 2 The prognosis for infants with symptomless hypoglycaemia is thougint to be good, ${ }^{3}$ and though evidence of possible cerebral damage has been found in $12 \%$ of infants in two series, ${ }^{15}$ neither contained a control group. In a recent study (unpublished) of 41 hypoglycaemic infants reviewed at a mean age of 51 months and compared with matched controls, no difference was found between the groups in the incidence of cerebral damage, behaviour disorders, or convulsions, and the mean intelligence quotients were identical. Twelve infants in this series had experienced asymptomatic hypoglycaemia, and all were normal at follow up.

While everyone is agreed that infants with "true" symptomatic hypoglycaemia require urgent treatment to avert cerebral damage, this condition usually occurs after the first day of life, whereas the majority of infants with asymptomatic hypoglycaemia have their low glucose levels confined to the first 24 hours of life, with a strong tendency to spontaneous correction within this period. ${ }^{6}$

In the present state of knowledge it would therefore appear reasonable to adopt a conservative policy with regard to asymptomatic hypoglycaemia during the first day of life, and resort to intravenous glucose only if spontaneous correction has not occurred within this period.-I am, etc.

Nevill Hall Hospital,

A. D. GRIfFiths

Abergavenny, Mon.

Scott, J. M., Archives of Diseases in Childhood, $1965,40,426$.

N. G., Edwards, P., and Jacobs, J fournal of Pathology and Bacteriology, 1966, 91,

Shelley, H. I., and Neligan, G. A., British Medical Bulletin, 1966, 22, 34

Haworth, J. C., and McRae, K. N., Canadian Medical Association fournal, 1965, 92, 861.

5 Chance, G. W., and Bower, B. D., Archives of Disease in Childhood, 1966, 44, 279. 6 Griffiths, A. D., Archives of Disease in Childhood,
1968, 43, 688.

\section{Twilight Sleep after Infarction}

SiR,--It may be of interest to hear of our experiences and impressions gained over the past 17 months at this hospital using the neuroleptic agent haloperidol in regular fairly high dose by intramuscular injection in the initial management of patients who have recently suffered acute myocardial infarction.

Sedation is generally considered desirable in these cases and morphine, heroin, etc. are useful in this respect as well as for their analgesic properties. It is written that the "psyche" may influence the occurrence of supraventricular arrhythmias, and it is possible that if supraventricular or ventricular arrhythmias are influenced by catecholamine levels then removing the sympathetic influence on the adrenal medulla and hence decreasing its secretions might decrease the incidence of these common postinfarction arrhythmias. Clearly, most patients having suffered an acute myocardial infarction are in a state of considerable mental 